\title{
Pesticide use and adult-onset asthma among male farmers in the Agricultural Health Study
}

\author{
J.A. Hoppin*, D.M. Umbach\#, S.J. London*, P.K. Henneberger", G.J. Kullmanף, \\ J. Coble ${ }^{+}$, M.C.R. Alavanja ${ }^{+}$, L.E. Beane Freeman ${ }^{+}$and D.P. Sandler*
}

ABSTRACT: Although specific pesticides have been associated with wheeze in farmers, little is known about pesticides and asthma.

Data from 19,704 male farmers in the Agricultural Health Study were used to evaluate lifetime use of $\mathbf{4 8}$ pesticides and prevalent adult-onset asthma, defined as doctor-diagnosed asthma after the age of 20 yrs. Asthma cases were categorised as allergic $(n=127)$ and nonallergic $(n=314)$ based on their history of eczema or hay fever. Polytomous logistic regression, controlling for age, state, smoking and body mass, was used to assess pesticide associations.

High pesticide exposure events were associated with a doubling of both allergic and nonallergic asthma. For ever-use, 12 individual pesticides were associated with allergic asthma and four with nonallergic asthma. For allergic asthma, coumaphos (OR 2.34; 95\% $\mathrm{Cl} 1.49-3.70$ ), heptachlor (OR 2.01; 95\% CI 1.30-3.11), parathion (OR 2.05; 95\% Cl 1.21-3.46), 80/20 mix (carbon tetrachloride/carbon disulfide) (OR 2.15; 95\% $\mathrm{Cl} 1.23-3.76$ ) and ethylene dibromide (OR 2.07; 95\% CI 1.02-4.20) all showed ORs of $>2.0$ and significant exposure-response trends. For nonallergic asthma, DDT (dichlorodiphenyltrichloroethane) showed the strongest association (OR 1.41; 95\% Cl 1.09-1.84), but with little evidence of increasing asthma with increasing use. Current animal handling and farm activities did not confound these results. There was little evidence that allergy alone was driving these associations. In conclusion, pesticides may be an overlooked contributor to asthma risk among farmers.

KEYWORDS: Allergy, farming, occupational exposure, pesticides, respiratory disease

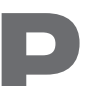

esticides may contribute to asthma among farmers [1], farm females (wives of farmers, some of whom work on the farm) [2] and insecticide applicators [3], but data on individual pesticides are limited to a few studies. Pesticide use, particularly that of organophosphate insecticides, has been associated with wheeze among US farmers [4], US commercial pesticide applicators [5] and Kenyan farmworkers [6], and with atopic asthma in farm females [2]. In guinea pigs, organophosphate insecticides induce airway hyperreactivity at doses below those causing acetylcholinesterase inhibition [7, 8]. These effects are stronger in allergen-sensitised animals [9].

Farmers are more likely to be diagnosed with nonatopic asthma than atopic asthma compared to other occupational groups [10]. This observation, along with evidence of differential response to pesticides in allergen-sensitised animals [9], indicates the importance of evaluating asthma risk factors separately based on atopic status. In a cross-sectional analysis of enrolment data from the Agricultural Health Study (AHS), the association of pesticide use with allergic and nonallergic asthma in farmers was evaluated. Self-reported allergy was used as a surrogate for atopy because clinical measurement of atopy was lacking.

\section{MATERIALS AND METHODS}

The AHS is a large prospective study of pesticide applicators from Iowa and North Carolina (both USA) and their spouses [11]. The study enrolled $>52,000$ licensed private pesticide appliers, mostly farmers, during 1993-1997. After completing the enrolment questionnaire, 22,916 (44\%) applicators returned a second postal questionnaire; applicators who did and did not return this

\section{AFFILIATIONS}

*Epidemiology Branch, and \#Biostatistics Branch, National Institute of Environmental Health Sciences, National Institutes of Health, Department of Health and Human Services, Research Triangle Park, NC,

${ }^{+}$Occupational and Environmental

Epidemiology Branch, National Cancer Institute, National Institutes of Health, Department of Health and Human Services, Rockville, MD, and "Division of Respiratory Disease Studies, National Institute for Occupational Safety and Health, Centers for Disease Control and Prevention, Department of Health and Human Services, Morgantown, WV USA.

\section{CORRESPONDENCE}

J.A. Hoppin

National Institute of Environmental

Health Sciences

Epidemiology Branch

MD A3-05

P.0. Box 12233

Research Triangle Park

NC 27709-2233

USA

E-mail: hoppin1@niehs.nih.gov

Received:

Jan 132009

Accepted after revision: June 112009

First published online:

June 182009 
second questionnaire were similar regarding demographics, farming practices and medical history [12]. The present analysis was limited to private applicators who returned both questionnaires because information on respiratory disease was obtained in the second questionnaire. The questionnaires are available online [13].

Participants provided information on medical history and potential confounders, including smoking, body mass, respiratory and allergic symptoms, and other respiratory diseases, as well as detailed information on their farming practices. Applicators provided detailed information on lifetime pesticide use for 50 pesticides (ever-use, frequency of use, number of years used and decade of first use). Individuals also provided information on their pesticide use practices, including application method, mixing, equipment repair and use of personal protective equipment (PPE). This information was used to create two metrics of lifetime pesticide use: lifetime days of use, and intensity-adjusted lifetime days of use. The intensity-adjusted metric accounted for potential differential exposure to pesticides based on application methods, mixing habits, repairs and use of PPE [14]. For general farming exposures, information was collected on current crops and animals raised, as well as current farm tasks and maintenance activities.

In addition to pesticide application information, there were also two measures indicative of ever having experienced elevated pesticide exposure: pesticide poisoning, and high pesticide exposure events (HPEEs). Pesticide poisoning was based on a self-report of doctor-diagnosed pesticide poisoning. A HPEE was determined based on the response to the question "Have you ever had an incident or experience while using any type of pesticide which caused you unusually high personal exposure?"

All male private applicators aged $\geqslant 20$ yrs with complete information on smoking, asthma history, age, body mass index (BMI) and HPEEs were included in the present analysis; female applicators were excluded because there were too few cases to evaluate $(n=487$ female applicators; $n=19$ asthma cases). Those subjects who reported doctor-diagnosed asthma after the age of 19 yrs were included as cases, and then further subdivided by allergic status based on a history of doctordiagnosed eczema or hay fever. Given the interest in adult asthma and occupational exposures, individuals diagnosed with asthma before the age of 20 yrs $(n=545)$ were excluded.

Polytomous logistic regression was used to evaluate associations between the farming exposures and prevalent adult-onset asthma. This permitted assessment of separate associations for allergic and nonallergic asthma simultaneously and formal testing of differences between odds ratios (ORs). Using goodness-of-fit tests, a base model was developed that consisted of age $(20-39,40-49,50-59$ or $\geqslant 60 \mathrm{yrs})$, state (IA or $\mathrm{NC})$, smoking status (current, past or never) and BMI $(<25,25$ 29 or $\geqslant 30 \mathrm{~kg} \cdot \mathrm{m}^{-2}$ ). Each exposure was assessed individually, adjusting for base-model covariates. The analysis was restricted to those exposures with at least five exposed cases. Exposure response was also evaluated by creating a three-level variable for each pesticide. For each pesticide, the distribution of intensity-adjusted days was split at the median among those who had ever used the pesticide to create two exposed groups (median or less, and greater than median); never-users were the referent group. These ordinal categories were used for Chisquared tests for trend.

In order to evaluate potential confounding by related exposures, pairwise Spearman correlations were first assessed between those exposure variables that were significant individually. Secondly, for pairs of moderately correlated variables $(r>0.3)$, both exposure variables were added simultaneously to the base model in order to assess changes in the OR estimates compared to modelling each exposure separately.

Two sensitivity analyses were conducted to evaluate the impact of the choice of disease definition. First, since the allergic-asthma group contained two different conditions (asthma and allergy), whether the results for pesticides might reflect an association with allergy alone was evaluated. The controls with allergy were removed from the comparison group and a polytomous model constructed with four groups: controls without allergy, allergy alone, asthma with allergy, and asthma alone. Secondly, as asthma can co-occur with other respiratory diseases, the analyses were repeated after excluding individuals with other respiratory diseases (i.e. chronic bronchitis and farmer's lung).

Analyses were performed using SAS v9.1 (SAS Institute, Inc., Cary, NC, USA) and AHS data set release P1REL0310.

\section{RESULTS}

Of the 19,704 male farmers included in the present analysis, $441(2.2 \%)$ individuals reported adult-onset asthma, with 127 classified as allergic and 314 classified as nonallergic. Males with asthma tended to be older and heavier and slightly more likely to have smoked than those without asthma (table 1). Wheeze was reported by $17 \%$ of controls and $74 \%$ of those with asthma. Allergic symptoms were most common in those with allergic asthma. Although use of any PPE for pesticide application was similar for those with and without asthma, individuals with asthma were much more likely to report the use of respiratory protection than those without asthma.

Although overall pesticide use history (e.g. total number of years pesticides applied) was not related to either type of asthma, a history of HPEEs was associated with an almost doubling of asthma risk for both types of asthma (OR 1.98, 95\% CI 1.30-2.99 for allergic asthma; OR, 1.96 95\% CI 1.49-2.56 for nonallergic asthma) (table 2). After adjusting for HPEEs and other base-model covariates, a history of doctor-diagnosed pesticide poisoning was nonsignificantly associated with an almost two-fold increased prevalence of allergic asthma (OR 1.95; 95\% CI 0.86-4.39). Owing to the strong association of HPEEs with asthma, all subsequent analyses controlled for HPEEs.

The asthma risk of 48 pesticides was evaluated among farmers (ziram and trichlorfon had too few exposed cases to be assessed). Although a minority of the cases were allergic asthma, more individual pesticides were associated with allergic asthma than with nonallergic asthma based on everuse (12 versus 4) (table 3$)$. For allergic asthma, three herbicides (2,4,5-TP (or fenoprop ( $R S$ )-2-(2,4,5-trichlorophenoxy)propionic acid), EPTC (S-ethyl dipropyl(thiocarbamate)) and paraquat), six insecticides (organochlorines: chlordane, heptachlor, 


\begin{tabular}{|c|c|c|c|}
\hline \multirow[t]{2}{*}{ TABLE 1} & \multicolumn{3}{|c|}{$\begin{array}{l}\text { Demographic, medical and farming } \\
\text { characteristics by adult-onset asthma status in } \\
19,704 \text { male farmers from the Agricultural Health } \\
\text { Study }\end{array}$} \\
\hline & Control & $\begin{array}{l}\text { Allergic } \\
\text { asthma }\end{array}$ & $\begin{array}{l}\text { Nonallergic } \\
\text { asthma }\end{array}$ \\
\hline Subjects $n$ & 19263 & 127 & 314 \\
\hline \multicolumn{4}{|l|}{ Age } \\
\hline 20-39 yrs & $5143(27)$ & $19(15)$ & $31(10)$ \\
\hline $40-49$ yrs & $5003(26)$ & $28(22)$ & $68(22)$ \\
\hline $50-59$ yrs & $4520(24)$ & $33(26)$ & $83(26)$ \\
\hline$\geqslant 60 \mathrm{yrs}$ & $4597(24)$ & $47(37)$ & $132(42)$ \\
\hline \multicolumn{4}{|l|}{ US state } \\
\hline lowa & $13046(68)$ & $90(71)$ & $226(72)$ \\
\hline North Carolina & $6217(32)$ & $37(29)$ & $88(28)$ \\
\hline \multicolumn{4}{|l|}{ Body mass index } \\
\hline$<25 \mathrm{~kg} \cdot \mathrm{m}^{-2}$ & $5023(26)$ & $25(20)$ & $68(22)$ \\
\hline $25-29 \mathrm{~kg} \cdot \mathrm{m}^{-2}$ & $9874(51)$ & $68(54)$ & $157(50)$ \\
\hline$\geqslant 30 \mathrm{~kg} \cdot \mathrm{m}^{-2}$ & $4366(23)$ & $34(27)$ & $89(28)$ \\
\hline \multicolumn{4}{|l|}{ Smoking history } \\
\hline Never & $10408(54)$ & $66(52)$ & $145(46)$ \\
\hline Past & $6359(33)$ & $54(43)$ & $143(46)$ \\
\hline Current & 2496 (13) & $7(6)$ & $26(8)$ \\
\hline \multicolumn{4}{|l|}{ Race } \\
\hline White & $18907(98)$ & $125(98)$ & $310(99)$ \\
\hline Other & $301(2)$ & $2(2)$ & $2(1)$ \\
\hline \multicolumn{4}{|l|}{ Education } \\
\hline $\begin{array}{l}\text { High school graduate } \\
\text { or less }\end{array}$ & $10811(57)$ & $64(53)$ & $198(64)$ \\
\hline Greater than high school & $8055(43)$ & $58(48)$ & $111(36)$ \\
\hline Grew up on a farm & $17728(92)$ & $118(93)$ & 287 (92) \\
\hline \multicolumn{4}{|l|}{$\begin{array}{l}\text { Respiratory and allergic } \\
\text { conditions }\end{array}$} \\
\hline Farmer's lung & $386(2)$ & $22(17)$ & $32(10)$ \\
\hline Chronic bronchitis & $603(3)$ & $33(26)$ & $86(28)$ \\
\hline Allergy ${ }^{\#}$ & $1856(10)$ & $127(100)$ & $0(0)$ \\
\hline Eczema & $406(2)$ & $36(28)$ & $0(0)$ \\
\hline Hay fever & $1519(8)$ & $105(83)$ & $0(0)$ \\
\hline Wheeze & $3152(17)$ & $105(84)$ & $216(70)$ \\
\hline Runny nose in past year & $12413(66)$ & $110(88)$ & $224(74)$ \\
\hline $\begin{array}{l}\text { Watery itchy eyes in } \\
\text { past year }\end{array}$ & $6343(34)$ & $85(69)$ & $119(40)$ \\
\hline \multicolumn{4}{|l|}{$\begin{array}{l}\text { PPE use } 10 \text { yrs before } \\
\text { enrolment }\end{array}$} \\
\hline Never used PPE & $4071(21)$ & $24(19)$ & $62(20)$ \\
\hline Cartridge respirator & $920(5)$ & $11(9)$ & $20(6)$ \\
\hline Dust mask & 2117 (11) & $20(16)$ & $56(18)$ \\
\hline Chemical gloves & $6971(36)$ & $49(39)$ & $119(38)$ \\
\hline \multicolumn{4}{|l|}{ PPE use" at enrolment } \\
\hline Never use PPE & $1768(9)$ & $15(12)$ & $31(10)$ \\
\hline Cartridge respirator & 1827 (9) & $14(11)$ & $25(8)$ \\
\hline Dust mask & $3937(20)$ & $36(28)$ & $95(30)$ \\
\hline Chemical gloves & $13361(69)$ & $92(72)$ & $208(66)$ \\
\hline
\end{tabular}

Data are presented as $n$ (\%) unless otherwise indicated. PPE: personal protective equipment. ${ }^{*}$ : history of doctor-diagnosed eczema or hay fever; $\because$ various PPE use is not mutually exclusive; individuals may report more than one method. and lindane; and organophosphates: diazinon, parathion, and coumaphos), one fungicide (captan) and two fumigants (ethylene dibromide and 80/20 mix (carbon tetrachloride and carbon disulfide)) were positively associated. For nonallergic asthma, one herbicide (petroleum oil) and three insecticides (organochlorine: DDT (dichlorodiphenyltrichloroethane); and organophosphates: phorate and malathion) were associated. No chemical was significantly associated with both asthma subgroups, although the ORs were almost identical in both groups for DDT and phorate. Four pesticides had ORs that were significantly different (coumaphos, paraquat, captan and lindane) between allergic and nonallergic asthma.

Exposure-response for pesticides and adult asthma was evaluated using three cumulative pesticide exposure metrics: total years of use, lifetime days of use, and intensity-adjusted lifetime days of use. The results for all metrics were similar, and, since the intensity-adjusted metric accounts for potential differences in exposure as a result of application practices, these results are presented in figure 1 for those pesticides with significant trend tests for either allergic or nonallergic asthma (table E1 of the online supplementary material includes the exposure-response models for all 48 pesticides evaluated). Of the 12 pesticides associated with allergic asthma, 10 also showed significant exposure-response trends, and, with the exception of chlordane and parathion, all had higher ORs at the higher exposure levels. The herbicides 2,4-D ((2,4-dichlorophenoxy)acetic acid) and 2,4,5-T ((2,4,5-trichlorophenoxy)acetic acid) exhibited significant exposure-response trends for allergic asthma, although the models for ever-use were nonsignificant. For nonallergic asthma, DDT and malathion showed significant dose-response trends.

It was also possible to assess the association related to use of treated seed for two fungicides (captan and metalaxyl). Captan-treated seed was associated with allergic asthma alone (OR 2.49; 95\% CI 1.42-4.36). Similarly, users of metalaxyltreated seed were more than five times more likely to report allergic asthma (OR 5.18; 95\% CI 2.48-10.8).

There was some evidence of correlations among specific pesticides and attenuation of some associations, but no strong evidence of confounding for any specific pesticide. The highest observed correlation among the controls was 0.37 for 2,4,5-T and 2,4,5-TP. The results for the ORs that changed in the multiple chemical models are presented below. For allergic asthma, parathion attenuated the association of paraquat (OR from 1.67 to $1.36 ; 95 \%$ CI $0.82-2.25)$. For the organochlorine pesticides, there was evidence of confounding for the associations with allergic asthma. Chlordane attenuated the associations with allergic asthma and DDT (OR from 1.42 to 1.17; 95\% CI 0.751.83 ) and diazinon (OR from 1.57 to $1.39 ; 95 \%$ CI $0.91-2.12$ ), whereas heptachlor attenuated the association of chlordane (OR from 1.77 to $1.53 ; 95 \%$ CI 1.02-2.31). In a model containing DDT, heptachlor and chlordane, the association for DDT was reduced to 1.05 (95\% CI 0.67-1.67), whereas the ORs for heptachlor and chlordane remained elevated (1.93 and 1.52, respectively). When heptachlor and chlordane were included in a model with diazinon, the OR for allergic asthma of diazinon was reduced to 1.25 (95\% CI 0.82-1.93), with little change in the estimates for heptachlor and chlordane (1.93 and 1.46, respectively). Similar attenuation of the exposure-response models for DDT were 


\begin{tabular}{|c|c|c|c|c|c|}
\hline \multirow[t]{3}{*}{ TABLE 2} & $\begin{array}{l}\text { pesticide exp } \\
\text { Study }\end{array}$ & variables with & gic and nonal & asthma in 19 & ale farmers from \\
\hline & \multirow[t]{2}{*}{ Controls n (\%) } & \multicolumn{2}{|c|}{ Allergic asthma } & \multicolumn{2}{|c|}{ Nonallergic asthma } \\
\hline & & Subjects $\mathbf{n}(\%)$ & OR $(95 \% \mathrm{CI})^{\#}$ & Subjects $\mathrm{n}(\%)$ & OR $(95 \% \mathrm{Cl})^{\#}$ \\
\hline Subjects $n$ & 19263 & 127 & & 314 & \\
\hline \multicolumn{6}{|l|}{ Pesticide application } \\
\hline $5-9$ days $\cdot y r^{-1}$ & $4649(25)$ & $29(23)$ & $0.78(0.46-1.32)$ & $69(23)$ & $0.95(0.66-1.37)$ \\
\hline $10-19$ days $\cdot y r^{-1}$ & $5683(31)$ & $41(32)$ & $0.94(0.57-1.54)$ & $97(33)$ & $1.18(0.84-1.67)$ \\
\hline 20-39 days $\cdot \mathrm{yr}^{-1}$ & $3303(18)$ & $22(17)$ & $0.92(0.52-1.65)$ & $55(19)$ & $1.29(0.87-1.90)$ \\
\hline$\geqslant 40$ days $\cdot \mathrm{yr}^{-1}$ & $1366(7)$ & $8(6)$ & $0.84(0.38-1.88)$ & $23(8)$ & $1.40(0.84-2.32)$ \\
\hline \multicolumn{6}{|l|}{ Pesticides applied } \\
\hline$\geqslant 31 \mathrm{yrs}$ & $2908(16)$ & $25(20)$ & $0.99(0.46-2.12)$ & $74(25)$ & $1.18(0.71-1.98)$ \\
\hline HPEE & $2744(14)$ & $30(24)$ & $1.98(1.30-2.99)$ & $73(23)$ & $1.96(1.49-2.56)$ \\
\hline No respiratory exposure & $1745(9)$ & $16(13)$ & $1.70(0.99-2.91)$ & $39(12)$ & $1.72(1.22-2.44)$ \\
\hline Respiratory exposure & $955(5)$ & $14(11)$ & $2.53(1.44-4.46)$ & $34(11)$ & $2.41(1.67-3.49)$ \\
\hline \multicolumn{6}{|l|}{ Decade of first HPEE } \\
\hline 1940s-1960s & $363(2)$ & $6(5)$ & $2.11(0.91-4.89)$ & $16(5)$ & $2.09(1.24-3.52)$ \\
\hline 1970s & $700(4)$ & $9(7)$ & $2.26(1.13-4.53)$ & $16(5)$ & $1.58(0.94-2.65)$ \\
\hline 1980s-1990s & $1419(7)$ & $14(11)$ & $2.10(1.18-3.73)$ & $30(10)$ & $1.95(1.32-2.88)$ \\
\hline Pesticide poisoning & $381(2)$ & $7(6)$ & $1.95(0.86-4.39)$ & $11(4)$ & $1.10(0.58-2.07)$ \\
\hline
\end{tabular}

found when chlordane and heptachlor were included in the model. None of the significant associations for nonallergic asthma could be explained by correlations with other pesticides.

There was little evidence of association between prevalent asthma and current farming activities (data not shown). Allergic asthma was associated with using gasoline as a cleaning solvent (OR 1.48; 95\% CI 1.04-2.13) and with performing veterinary services (OR 1.51; 95\% CI 1.03-2.21). Veterinary services (OR $0.77 ; 95 \%$ CI 0.60-0.97) and driving combine harvesters (OR 0.72; 95\% CI 0.53-0.97) were inversely associated with nonallergic asthma. There were no positive associations between nonallergic asthma and current farming activities. Current farm activities did not appear to confound the pesticide results.

In order to determine whether or not the differential results for allergic and nonallergic asthma were due to allergy alone, allergic individuals were removed from the control group and the analysis was rerun (table E2 of online supplementary material). Although some pesticides were associated with allergy alone, the ORs were stronger for allergic asthma than for allergy alone for all pesticides associated with allergic asthma in earlier models.

In order to evaluate whether or not the present results were related to asthma, or to some comorbid respiratory disease, all individuals with chronic bronchitis and farmer's lung were excluded and the models were rerun (table E3 of online supplementary material). A larger proportion of asthma cases, both allergic and nonallergic, reported some other respiratory illness compared to controls ( $35 \%$ versus $5 \%$ ). With these individuals excluded, the ORs for allergic asthma were significant for five pesticides $(2,4,5-\mathrm{T}$, parathion, coumaphos, captan and 80/20 mix), and similar to the values reported in table 3. For four other pesticides, the resulting ORs were attenuated: heptachlor (OR from 2.01 to 1.30), chlordane (OR from 1.77 to 1.27 ), paraquat (OR from 1.67 to 1.36 ), and 2,4,5-TP (OR from 1.91 to 1.68). Of the four pesticides significantly associated with nonallergic asthma, only phorate remained significant when the individuals with other lung diseases were removed. After excluding the other respiratory diseases, the OR for fonofos and nonallergic asthma increased from 1.22 to 1.39 (95\% CI 1.00-1.94), and the association between petroleum oil and nonallergic asthma went away (OR from 1.35 to 1.15).

\section{DISCUSSION}

Grains, hays and animals have been identified as important aetiological agents for respiratory disease among farmers for centuries [15]; however, few studies have evaluated the association between specific pesticides and respiratory disease. Here, we offer additional evidence that pesticides may also be a risk factor for asthma among farmers. Building on previous work in farmers [1], farmworkers [6, 16, 17], pesticide applicators [3] and farm females [2], we observed that specific pesticides were associated with allergic asthma, and that selfreported HPEEs were associated with both allergic and nonallergic asthma. We also saw associations with lifetime days of use of individual pesticides, suggesting an exposure-response relationship. 
TABLE 3 Associations of ever-use of individual pesticides with allergic and nonallergic asthma in 19,704 male farmers in the Agricultural Health Study

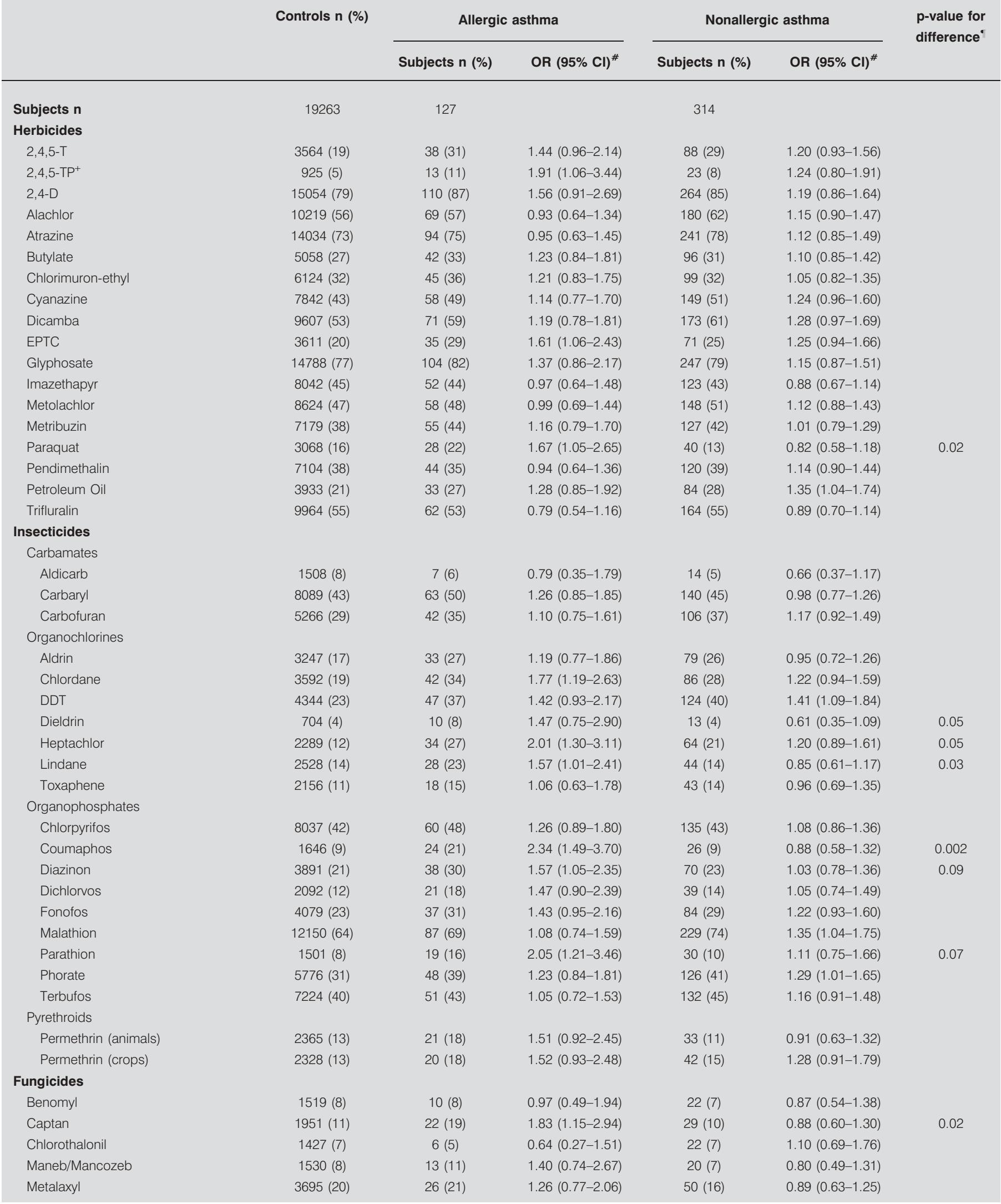




\section{TABLE 3 Continued.}

\begin{tabular}{|c|c|c|c|c|c|c|}
\hline & \multirow[t]{2}{*}{ Controls n (\%) } & \multicolumn{2}{|c|}{ Allergic asthma } & \multicolumn{2}{|c|}{ Nonallergic asthma } & \multirow{2}{*}{$\begin{array}{l}\text { p-value for } \\
\text { difference }\end{array}$} \\
\hline & & Subjects n (\%) & OR $(95 \% \mathrm{Cl})^{\#}$ & Subjects n (\%) & OR $(95 \% \mathrm{Cl})^{\#}$ & \\
\hline \multicolumn{7}{|l|}{ Fumigants } \\
\hline $80 / 20 \mathrm{mix}^{5}$ & $818(4)$ & $15(12)$ & $2.15(1.23-3.76)$ & $24(8)$ & $1.25(0.81-1.93)$ & \\
\hline Aluminum phosphide & $641(3)$ & $6(5)$ & $1.34(0.58-3.06)$ & $12(4)$ & $1.14(0.63-2.04)$ & \\
\hline Ethylene dibromide & $818(4)$ & $10(8)$ & $2.07(1.02-4.20)$ & $16(5)$ & $1.25(0.73-2.15)$ & \\
\hline Methyl bromide & $2838(15)$ & $16(13)$ & $0.86(0.46-1.60)$ & $41(13)$ & $0.98(0.66-1.45)$ & \\
\hline
\end{tabular}

2,4,5-T: (2,4,5-trichlorophenoxy)acetic acid; 2,4,5-TP: (RS)-2-(2,4,5-trichlorophenoxy)propionic acid; 2,4-D: (2,4-dichlorophenoxy)acetic acid; EPTC: S-ethyl dipropyl(thiocarbamate); DDT: dichlorodiphenyltrichloroethane. ${ }^{*}$ : adjusted for age, US state, smoking, high pesticide exposure events and body mass index; ": only shown if $p<0.1{ }^{+}$: fenoprop; ${ }^{\text {s: }}$ carbon tetrachloride/carbon disulfide.

HPEEs are infrequent events on farms; however, $14 \%$ of farmers report having at least one HPEE in their lifetime. These events often do not result in seeking care for pesticide poisoning [18]. HPEEs were an important risk factor for both allergic and nonallergic asthma. Although we saw no evidence of an interaction between HPEEs and individual pesticides, a history of HPEEs was an important confounder of the pesticide findings. Before adjusting for HPEEs, 14 pesticides were associated with allergic asthma and 10 with nonallergic asthma. HPEEs have been associated with a two-fold increased prevalence of the respiratory diseases chronic bronchitis [19] and farmer's lung [20], as well as with a number of neurological outcomes, including depression [21] and neurological symptoms [22].
The present findings are consistent with results from other respiratory analyses from the AHS and other studies. The herbicides EPTC and paraquat were associated with wheeze among farmers [4]. Paraquat was also associated with allergic asthma among farm females [2], as well as respiratory symptoms and oxygen desaturation in studies of farmworkers in Costa Rica and South Africa [23, 24]. Paraquat has also been associated with allergic symptoms in grape farmers in Crete (Greece) [25]. The organochlorine insecticides DDT and lindane were associated with allergic asthma in farm females; DDT was also associated with nonallergic asthma among farm females. The organophosphate insecticides coumaphos and parathion were associated with allergic asthma in farm females; coumaphos was associated with wheeze in the commercial pesticide

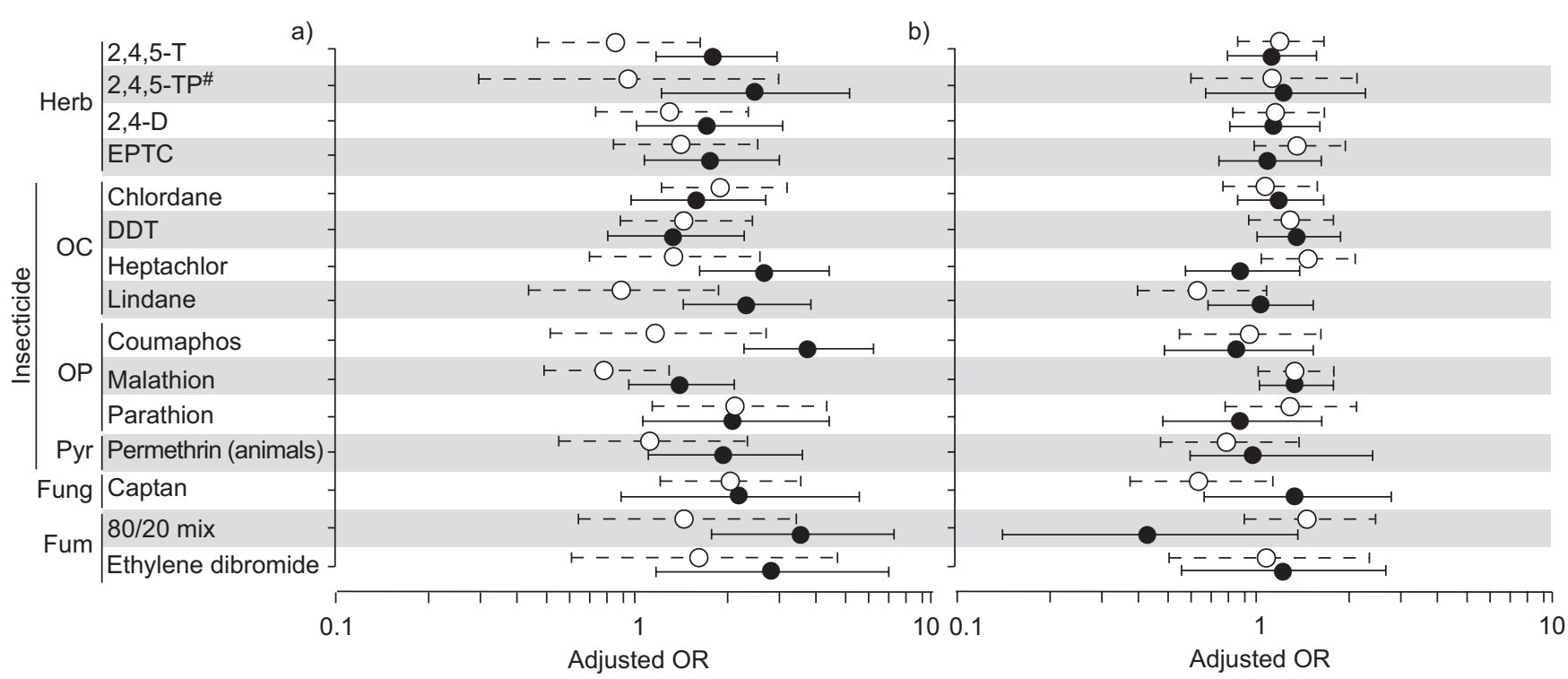

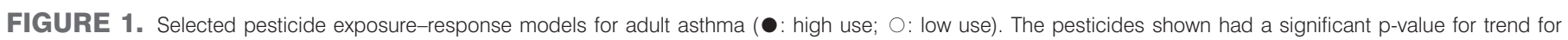

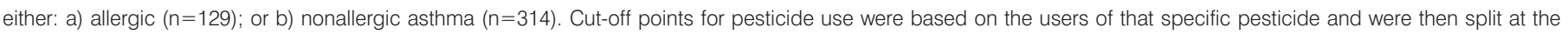

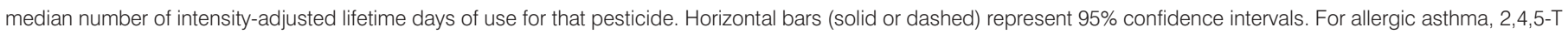

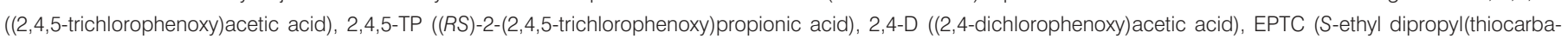

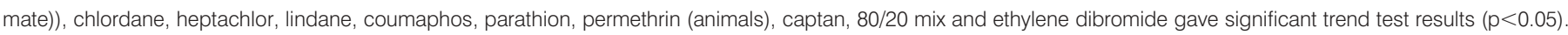

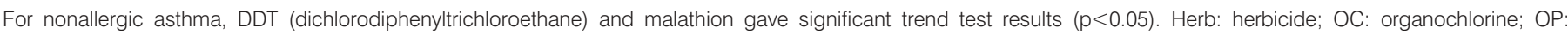
organophosphate; Pyr: pyrethroid; Fung: fungicide; Fum: fumigant; OR: odds ratio. * : fenoprop. 
applicators [5], whereas parathion was associated with wheeze among farmers [4]. Other investigators have also found organophosphate insecticides to be associated with asthma or wheeze. Saskatchewan (Canadian) farmers who used organophosphate insecticides showed increased asthma, although the association was stronger with users of carbamate insecticides [1]; the present findings suggest stronger evidence for organophosphates. Farmworkers with depressed acetyl cholinesterase activity (a measure of organophosphate exposure) show increased respiratory symptoms $[6,17]$.

For the pesticides associated with nonallergic asthma, all were previously associated with wheeze or asthma in the AHS. Petroleum oil was associated with nonallergic asthma in farm females [2], and with wheeze among farmers and commercial pesticide applicators $[4,5]$. Both phorate and malathion were associated with allergic, but not nonallergic, asthma in farm females [2], and were associated with wheeze. One pesticide that was not associated with asthma in the present analysis was carbofuran; this pesticide was strongly associated with asthma among Saskatchewan farmers [1] and among AHS farm females [2].

Allergic asthma is far less common in adults than in children [26], and far less common in farmers than in other occupational groups [10]. However, in the present study, the associations with pesticides were much stronger for allergic than nonallergic asthma; our analysis of farm females [2] showed a similar relationship. Pesticides may modulate inflammatory responses to farm bioaerosols, such as endotoxin and allergens. Allergensensitised guinea pigs exhibited a lower threshold for parathioninduced airway responsiveness [9]. Carbaryl enhanced the allergenicity of dust mites in animals [27]. Captan and metalaxyl, both commonly used seed treatments, were strongly associated with allergic asthma when pre-applied to seed, suggesting a possible interaction of allergen and pesticide. Given the variety of pesticides associated with allergic asthma, the possibility cannot be ruled out that some common ingredient in the pesticidal products may explain these results.

We relied on self-reported exposure and outcome data. Farmers provide reliable information regarding their personal pesticide use $[28,29]$. By using an intensity-adjusted exposure metric, we were able to account for potential differences in exposure resulting from different application practices. The intensity metric is able to distinguish between high and low exposure intensity in field studies [30]; thus we were better able to classify individuals with respect to total exposure. Even though individuals with allergic asthma appeared to have reduced their exposure through fewer pesticide application days annually and increased use of respiratory protection, we were still able to observe significant exposure-response trends using this intensity metric. We have no reason to believe that pesticide use reporting would differ by asthma or allergy status. Self-reported doctor-diagnosed asthma has been shown to be a reliable and valid end-point [31, 32]. Among farmers, self-reported asthmatic subjects exhibit a higher symptom prevalence and lower lung function than nonasthmatics [1]. In the present sample, individuals with asthma were more likely to report wheeze than those without asthma, and individuals classified as allergic had more allergic symptoms than those classified as nonallergic. Allergy was defined as a history of doctor-diagnosed eczema or hay fever. Although we used no clinical measures to assess allergic status, such as skinprick testing or immunoglobulin E measurement, our measure is similar to ones used previously. The two case groups are based on the responses to three questions (asthma, eczema and hay fever), similar to the classification that UPTON et al. [26] used to define atopic and nonatopic asthma among adults in Scotland (UK). We classified $71 \%$ of adult asthma among farmers as nonallergic, an estimate very similar to the $70 \%$ reported among Norwegian adults in whom atopy was defined by immunoglobulin E [10]. By limiting our definition of allergy to those with doctor-diagnosed hay fever or eczema, it is likely that these individuals received allergy testing at the time of diagnosis; however, we have no data to evaluate that.

Farms represent a complex occupational setting with opportunities for a number of concurrent exposures, including multiple pesticides. When correlated pesticides were taken into account, the associations for DDT were attenuated, but the associations for other organochlorines remained elevated. Although we saw no strong associations with current farm activities, data on lifetime farming exposures to animals, hays and grains, which may contribute to asthma, are lacking. Hence, the findings for some specific pesticides may be confounded by previous exposures. For example, coumaphos is an insecticide used on animals and thus may be a surrogate for historical animal exposures. However, a majority of the pesticides associated with asthma have not been used in animal production. Given the lack of commonality to the pesticides, both in their use patterns and toxicity, it seems unlikely that all of the findings are due to uncontrolled confounding.

In this analysis of 19,704 male farmers with good information on lifetime pesticide use, specific pesticides were associated with allergic asthma. One of the pesticides, parathion, has also been associated with allergic asthma in farm females, wheeze in farmers and airway hyperresponsiveness in allergen-sensitised animals. Additionally, individuals with a history of a HPEE were twice as likely to report having adult-onset asthma. As the analysis was cross-sectional, we cannot evaluate the temporal order of exposure and disease; however, given the consistency of the results for epidemiological and animal studies, more detailed studies are warranted to identify patterns of pesticide use that may contribute to asthma among farmers.

\section{SUPPORT STATEMENT}

This study was supported by the Intramural Research Program of the National Institutes of Health, National Institute of Environmental Health Sciences (Z01-ES049030) and National Cancer Institute (Z01CP010119).

The findings and conclusions of this report are those of the authors and do not necessarily represent the views of the National Institute for Occupational Safety and Health (NIOSH). Mention of any company or product does not constitute endorsement by NIOSH.

\section{STATEMENT OF INTEREST}

None declared.

\section{ACKNOWLEDGEMENTS}

The authors thank S. Long (Westat, Rockville, MD, USA) for data analysis. This work could not have happened without the hard work of the Iowan field station (University of Iowa, Iowa City, IA, USA; C. Lynch and E. Heywood) and North Carolinian field station (Battelle 
Public Health Research Institute, Durham, NC, USA; C. Knott and M. Hayslip) and the Agricultural Health Study (AHS) Coordinating Center (Rockville, MD, USA; B. Laimon, M. Dunn, K. Torres and S. Legum). We also thank the AHS cohort members for their contribution to this work.

\section{REFERENCES}

1 Senthilselvan A, McDuffie HH, Dosman JA. Association of asthma with use of pesticides - results of a cross-sectional survey of farmers. Am Rev Respir Dis 1992; 146: 884-887.

2 Hoppin JA, Umbach DM, London SJ, et al. Pesticides and atopic and nonatopic asthma among farm women in the Agricultural Health Study. Am J Respir Crit Care Med 2008; 177: 11-18.

3 Beard J, Sladden T, Morgan G, et al. Health impacts of pesticide exposure in a cohort of outdoor workers. Environ Health Perspect 2003; 111: 724-730

4 Hoppin JA, Umbach DM, London SJ, et al. Chemical predictors of wheeze among farmer pesticide applicators in the Agricultural Health Study. Am J Respir Crit Care Med 2002; 165: 683-689.

5 Hoppin JA, Umbach DM, London SJ, et al. Pesticides associated with wheeze among commercial pesticide applicators in the Agricultural Health Study. Am J Epidemiol 2006; 163: 1129-1137.

6 Ohayo-Mitoko GJA, Kromhout H, Simwa JM, et al. Self reported symptoms and inhibition of acetylcholinesterase activity among Kenyan agricultural workers. Occup Environ Med 2000; 57: 195-200.

7 Fryer AD, Lein PJ, Howard AS, et al. Mechanisms of organophosphate insecticide-induced airway hyperreactivity. Am J Physiol Lung Cell Mol Physiol 2004; 286: L963-L969.

8 Lein PJ, Fryer AD. Organophosphorus insecticides induce airway hyperreactivity by decreasing neuronal M2 muscarinic receptor function independent of acetylcholinesterase inhibition. Toxicol Sci 2005; 83: 166-176.

9 Proskocil BJ, Bruun DA, Lorton JK, et al. Antigen sensitization influences organophosphorus pesticide-induced airway hyperreactivity. Environ Health Perspect 2008; 116: 381-388.

10 Eduard W, Omenaas E, Bakke PS, et al. Atopic and non-atopic asthma in a farming and a general population. Am J Ind Med 2004; 46: 396-399.

11 Alavanja MC, Sandler DP, McMaster SB, et al. The Agricultural Health Study. Environ Health Perspect 1996; 104: 362-369.

12 Tarone RE, Alavanja MC, Zahm SH, et al. The Agricultural Health Study: factors affecting completion and return of self-administered questionnaires in a large prospective cohort study of pesticide applicators. Am J Ind Med 1997; 31: 233-242.

13 Agricultural Health StudyFull text of questionnaires. www. aghealth.org/questionnaires.html Date last updated: December, 2008. Date last accessed: October 14, 2009.

14 Dosemeci M, Alavanja MC, Rowland AS, et al. A quantitative approach for estimating exposure to pesticides in the Agricultural Health Study. Ann Occup Hyg 2002; 46: 245-260.

15 Schenker MB, Christiani D, Cormier Y, et al. Respiratory health hazards in agriculture. Am J Respir Crit Care Med 1998; 158: Suppl. S, S1-S76.
16 Castro-Gutierrez N, McConnell R, Andersson K, et al. Respiratory symptoms, spirometry and chronic occupational paraquat exposure. Scand J Work Environ Health 1997; 23: 421-427.

17 Hernandez AF, Casado I, Pena G, et al. Low level of exposure to pesticides leads to lung dysfunction in occupationally exposed subjects. Inhal Toxicol 2008; 20: 839-849.

18 Bell EM, Sandler DP, Alavanja MC. High pesticide exposure events among farmers and spouses enrolled in the Agricultural Health Study. J Agric Saf Health 2006; 12: 101-116.

19 Hoppin JA, Valcin M, Henneberger PK, et al. Pesticide use and chronic bronchitis among farmers in the Agricultural Health Study. Am J Ind Med 2007; 50: 969-979.

20 Hoppin JA, Umbach DM, Kullman GJ, et al. Pesticides and other agricultural factors associated with self-reported farmer's lung among farm residents in the Agricultural Health Study. Occup Environ Med 2007; 64: 334-341.

21 Beseler C, Stallones L, Hoppin JA, et al. Depression and pesticide exposures among private pesticide applicators enrolled in the Agricultural Health Study. Environ Health Perspect 2008; 116: 17131719.

22 Kamel F, Engel LS, Gladen BC, et al. Neurologic symptoms in licensed pesticide applicators in the Agricultural Health Study. Hum Exp Toxicol 2007; 26: 243-350.

23 Dalvie MA, White N, Raine R, et al. Long-term respiratory health effects of the herbicide, paraquat, among workers in the Western Cape. Occup Environ Med 1999; 56: 391-396.

24 Schenker MB, Stoecklin M, Lee K, et al. Pulmonary function and exercise-associated changes with chronic low-level paraquat exposure. Am J Respir Crit Care Med 2004; 170: 773-779.

25 Chatzi L, Alegakis A, Tzanakis N, et al. Association of allergic rhinitis with pesticide use among grape farmers in Crete, Greece. Occup Environ Med 2007; 64: 417-421.

26 Upton MN, McConnachie A, McSharry C, et al. Intergenerational 20 year trends in the prevalence of asthma and hay fever in adults: the Midspan family study surveys of parents and offspring. BMJ 2000; 321: 88-92.

27 Dong W, Gilmour MI, Lambert AL, et al. Enhanced allergic responses to house dust mite by oral exposure to carbaryl in rats. Toxicol Sci 1998; 44: 63-69.

28 Blair A, Zahm SH. Patterns of pesticide use among farmers: implications for epidemiologic research. Epidemiology 1993; 4: 55-62.

29 Hoppin JA, Yucel F, Dosemeci M, et al. Accuracy of self-reported pesticide use duration information from licensed pesticide applicators in the Agricultural Health Study. J Expo Anal Environ Epidemiol 2002; 12: 313-318.

30 Coble J, Arbuckle T, Lee W, et al. The validation of a pesticide exposure algorithm using biological monitoring results. J Occup Environ Hyg 2005; 2: 194-201.

31 Burney PG, Laitinen LA, Perdrizet S, et al. Validity and repeatability of the IUATLD (1984) Bronchial Symptoms Questionnaire: an international comparison. Eur Respir J 1989; 2: 940-945.

32 Jenkins MA, Clarke JR, Carlin JB, et al. Validation of questionnaire and bronchial hyperresponsiveness against respiratory physician assessment in the diagnosis of asthma. Int J Epidemiol 1996; 25: 609-616. 